\title{
Benefits of Listening for Harmony on the Performance of Wind Instrument Beginners
}

\author{
Prapassorn Puangsamlee ${ }^{1}$, Kyle Fyr ${ }^{2}$ \\ College of Music, Mahidol University, Thailand \\ Phutthamonthon Nakhonpathom, 73170 Thailand \\ e-mail: pp.pom.flute@gmail.com ${ }^{1}$, kyle.fyr@ mahidol.ac.th ${ }^{2}$
}

Published online: 5 September 2018

Cite this article (APA): Puangsamlee, P. \& Fyr, K. (2018). Benefits of listening for harmony on the performance of wind instrument beginners. Malaysian Journal of Music, 7, 100-116.

\begin{abstract}
One of the greatest challenges for wind instrument beginners is developing the ability to listen for harmony when practicing and performing. Even though harmony is one of the most fundamental musical elements in western art music, attaining such a listening proficiency can be especially difficult for wind instrument beginners who are much more accustomed to focusing on a single melodic line, which can in turn have significant implications for the students' performance. This study accordingly investigated the benefits of listening for harmony on first-year wind instrument students in the Young Artists Music Program (YAMP) at the College of Music, Mahidol University, Thailand. The students who participated in the study were selected because they had no previous experience playing harmonic instruments and received a score of no higher than 69 percent on their aural skills entrance exams. The main purpose of the study was to explore the ways in which developing the students' aptitude in listening for harmony might aid in improving their basic performance. After gathering information from observation, sound recording, field notes and interviews, the results from this study indicate that developing the students' skills in listening for harmony can benefit their intonation, tone quality and sense of melodic direction, all of which are important aspects of wind instrument performance.
\end{abstract} beginners,

Keywords: harmony, intonation, melodic direction, tone quality, wind instrument

\section{Introduction}

The famed French-American oboist Marcel Tabuteau noted that "As good advice to my young friends - wind players - I want to warn them against the general tendency to try to imitate without having had the basic technique necessary to perform" (McGill, 2007). A convincing argument can be made that the 'basic technique' 
Tabuteau mentions could be more broadly interpreted to mean a combination of technical skill and musical knowledge that must be developed prior to performance. Just what are some of the fundamental techniques and areas of musical knowledge that are most important for wind instrument beginners, however?

This article argues that harmony is one of the most fundamental musical elements in Western music that can be can used to enhance the performance of wind instrument beginners. Though the primary focus for wind instrument students is often on playing single-line melodies, harmony is an essential, defining feature of those melodies - an element that, as authors such as Kostka, Payne, and Almen (2013) point out, also applies to solo pieces without accompaniment. Even though there is no single generally accepted method for how wind instrument students should play a single melodic line based on the harmony, there is nevertheless a good deal of previous scholarship which indicates how important harmony is for musicians in many ways. For example, harmony has been shown to affect pitch perception and is noted for driving listeners' expectations of direction in music (Kim, 2013; Laitz \& Bartlette, 2010; Ratner, 1983).

The process of developing skills in listening for harmony among wind instrument beginners is related to a variety of factors tied to their musical experiences. Because wind instruments can generally be considered melodic rather than harmonic instruments, beginning wind instrument students tend to be unfamiliar with the notion of playing a single melodic line while thinking about the harmony at the same time. Wind instrument students with previous experience playing harmonic instruments have already had some opportunity to develop their skills in listening for harmony, however, this is a mitigating factor worth considering. Finally, it is worth keeping in mind that hearing and listening are not the same thing, as listening is more related to understanding in music than hearing is (Jensen, 2000; Wedin, 2015). In order to examine the benefits of listening for harmony on young wind instrument students, three first-year students from the Young Artists Music Program (YAMP) at the College of Music, Mahidol University were selected to participate in a case study. The students selected for the study accordingly had no previous experience playing harmonic instruments. Since one of the main objectives of the study was to explore how listening for harmony could benefit students' performance, students were selected from among those who received scores of no higher than 69 percent on the aural skills portion of their entrance exams, meaning that the aural skills of the selected students showed room for improvement. Students' skills in listening for harmony are admittedly not something that can be developed overnight, so the study employed a multi-step process in which the participants' harmony listening skills were examined in the context of working on basic wind techniques outlined by David McGill (2007), which consisted of long note exercises, scales and phrasing. Data was then collected throughout the observation process using a variety of tools, as detailed in the methodology section of this article. Though this study was limited to a group of selected participants from the Young Artists Music Program (YAMP) at the College of Music, Mahidol University (Thailand), the results seem to indicate potential benefits for young wind instrument students in general. 


\section{Background}

\section{Basic Wind Instrument Technique}

McGill advocates that the goal of the instrumentalist "is to help the public to forget the instrument and immerse themselves in the music" (2007, p. 161). He proposes that reaching this goal starts with basic techniques such as long note exercises, scales and phrasing. The conceptual framework for this study is accordingly based on the idea of merging technical skill and musical knowledge through working on these three basic wind techniques, as summarised in Figure 1.

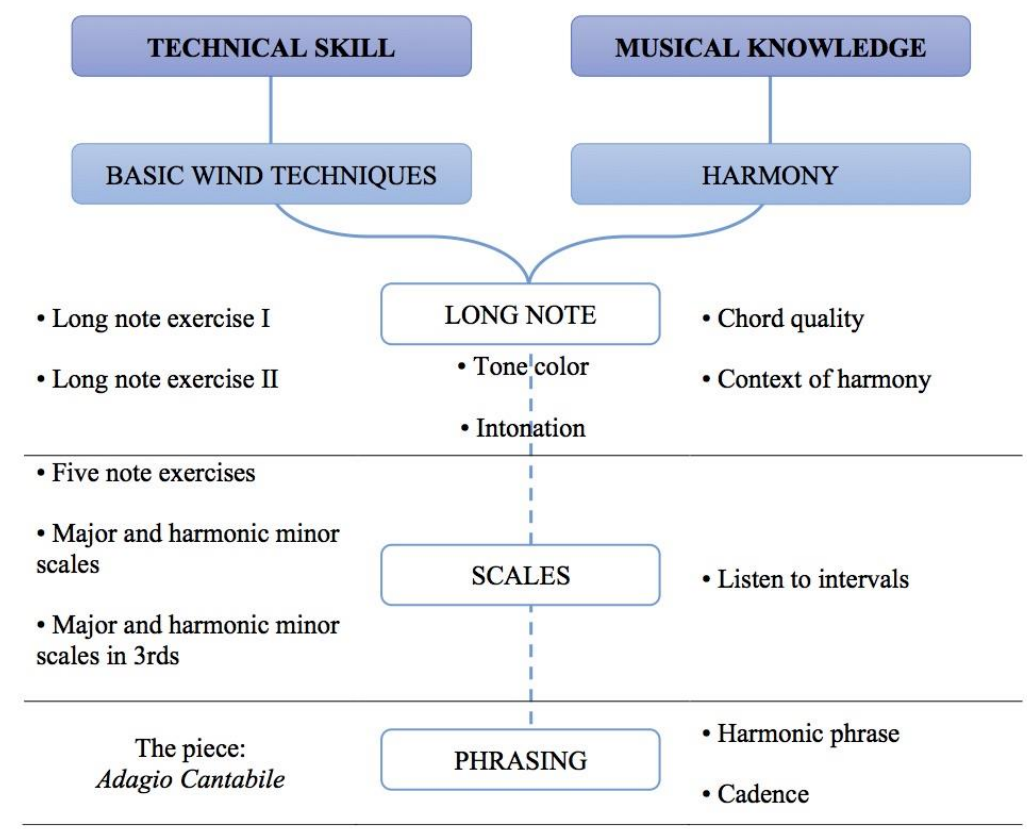

Figure 1. The conceptual framework and the series of basic wind techniques employed in this study.

Long note exercises. Long note exercises are some of the most difficult practice tasks for wind players, but these exercises help wind players to develop good air control as well as working on their dynamic range, tone color and intonation. McGill (2007) notes that these exercises can also be useful in helping wind instrument students in make music with expression.

Scales. Working on scales is a basic exercise that of course plays a major role in many students' practice routines. McGill (2007) advocates playing scales 
musically, and not simply seeing them as exercises to build technique, suggesting that one way to accomplish this goal is to focus on listening to the intervals within the scales.

Phrasing. For the purposes of this study, phrasing refers to the process by which performers divide successive notes into groups (Sadie, S., \& Tyrrell, J., 2001; Kennedy, M., \& Kennedy, J. B., 2007). The eminent American oboist John de Lancie remarked, "Everybody talks about music being the international language. So when you play to other musicians ... you should play in such a fashion so [they] ... could be taking dictation and would have no problem understanding what you're doing" (McGill, 2007). This quote seems to imply that musical phrasing can support both musicians' and listeners' understanding in music. It is therefore an important skill for wind instrument students to learn to divide musical phrases as clearly as possible, and perhaps the most important factor in doing so is harmony.

\section{The Importance of Listening for Harmony}

The importance of harmony is a long-standing topic in music theory scholarship. One of the most prominent music theorists to explore the relationship between melody and harmony was Jean-Philippe Rameau, who posited that melody and harmony are associated with each other based on the rules of harmony. Moreover, he advocated that, when composing music, melodies should not stand alone, but each part should relate to each other, causing him to conclude, therefore, that "It is harmony then that guides us and not melody" (Rameau, 1971, pp. 145-146). As previously noted, however, this can be a difficult concept to understand for young wind instrument students whose primary focus is on playing single-line melodies.

Some more recent studies also underscore the importance of listening for harmony in performance, a topic closely related to the study presented here. For example, the musical context of harmony has been shown to affect pitch perception and is noted for driving listeners' expectations of direction in music (Kim, 2013; Taher, 2012). Knowledge of harmonic context has similarly been shown to help music students understand characteristics of sound as tension or release (Servias, 2010). Furthermore, a number of authors, such as Karpinski (2000) and Lisk (1996), describe how musicians' skills in listening for harmony can help produce more sensitive, meaningful performances, and although these listening skills are difficult and time-consuming to achieve, the payoff is substantial.

\section{Methodology}

A qualitative case study was employed to investigate the benefits of listening for harmony on young wind instrument students, following the criteria outlined by Ashley (2008), Creswell (2013), Thomas (1988) and Yin (2009). The participants in the study were first-year wind instrument students from the Young Artists Music Program (YAMP) at the College of Music, Mahidol University, Thailand, who had no prior experience playing a harmonic instrument and who received a score of no 
higher than 69 percent on the aural skills portion of the Thailand International Music Examination (TIME), which YAMP uses to assess students' knowledge and skills in music theory and aural prior to entering the program. Five students at YAMP were found to fit the above criteria, and three of these students agreed to participate in this study. There were twenty observation sessions for each participant, with the duration of each session approximately 20-30 minutes. An important priority for the study was to observe the benefits of listening for harmony through the students' practice, without any instruction, guidance or suggestion from the researcher.

\section{Data Collection}

Data for the study was collected in a variety of ways, as summarised below.

Observation. Observation was the main process used in this study to collect data. The researcher was present while the participants practiced the basic technique exercises and recorded their practice sessions, but did not guide the students or give any suggestions on how to practice the exercises.

Interviews. Interviews were also conducted to obtain additional information from the participants to supplement the data from the observations. The interviews provided the opportunity to gain further perspectives on the participants' experiences while practicing the basic technique exercises with regard to the following:

a) Participants were asked to describe how they thought about harmonic context while playing long notes (specifically, what were their reasons for choosing particular notes, what went through their minds as they played the notes, and how did this process correspond to their previous practice experiences).

b) In addition, participants were asked to describe their thought processes and what they were trying to listen for when playing a melody without hearing the harmonic reference sounds.

Basic technique exercises. A few basic technique exercises were used in this study to investigate how listening for harmony might improve basic performance, and were developed with a focus on fundamental wind techniques. The basic technique exercises were of three types, with four different purposes, as follows:

a) Long note: Two sets of long note exercises were used to investigate how the participants listened in the context of harmony while playing a single note. In Long note exercise I, the participants were asked to play a note while imagining a harmonic context of their choice; in Long note exercise II, the participants were first asked to imagine a harmonic context provided by the 
researcher before playing a given note, and were later provided a reference sound. The long note exercise pattern is shown in Figure 2.

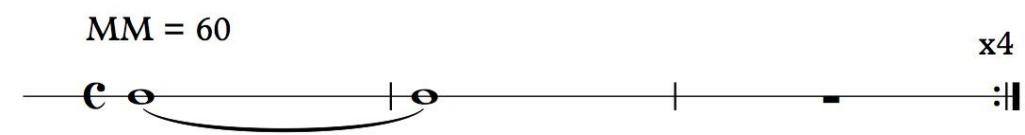

Figure 2. Long note exercise

b) Scales: The participants were first asked to play five-note patterns consisting of the first five notes of a major and minor scale, ascending and descending. Later, the participants were asked to play full major and harmonic minor scales, ascending and descending, and finally they were asked to play scales in thirds. In each case, the participants were asked to play along with a variety of harmonic progressions in order to investigate the participants' sense of harmonic change while playing the same melodic pattern (see Figures 3 through 8).

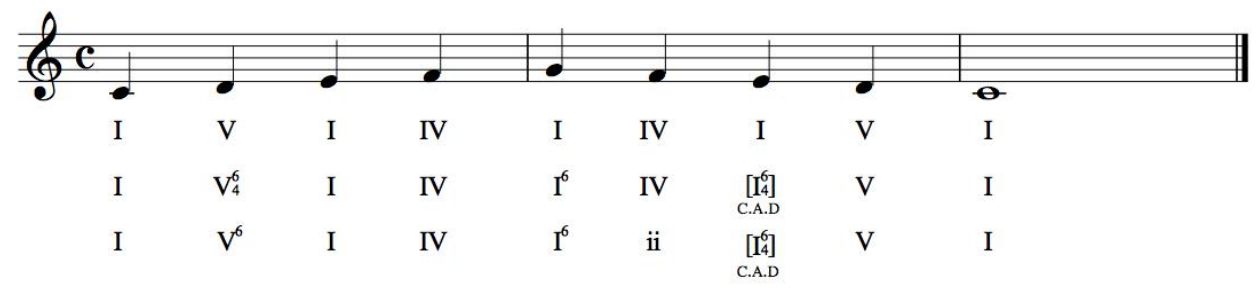

Figure 3. Five-note scale patterns, major key

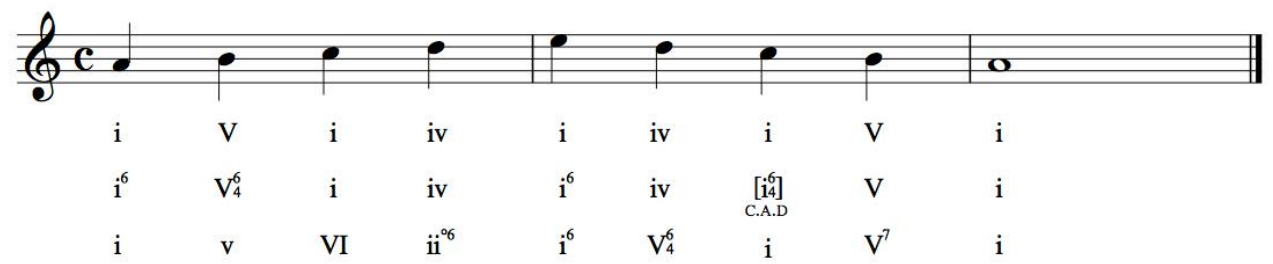

Figure 4. Five-note scale patterns, minor key 


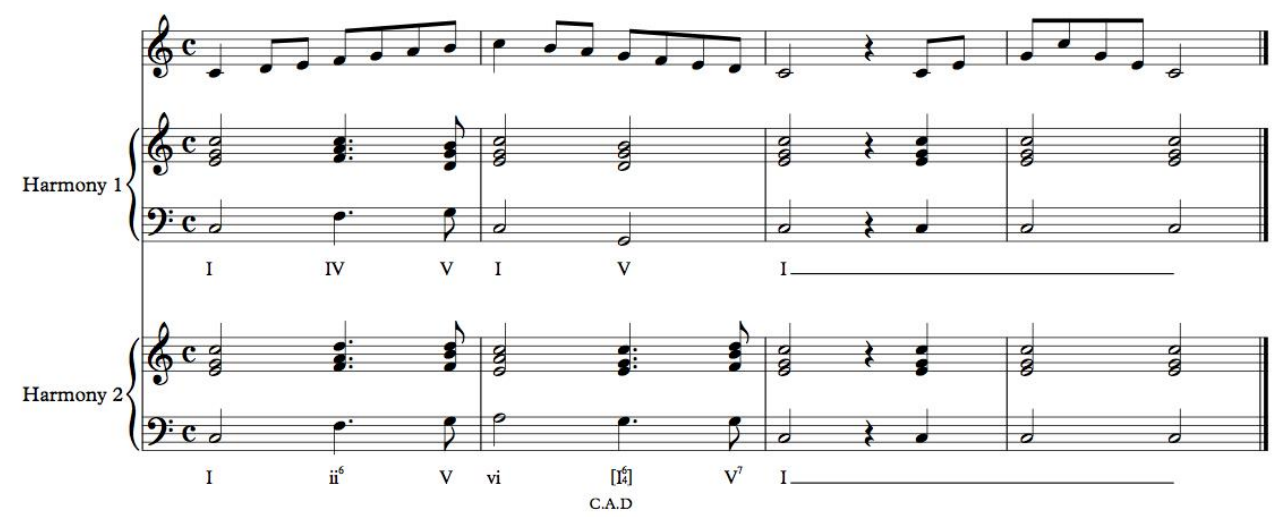

Figure 5. An example of a harmonised major scale

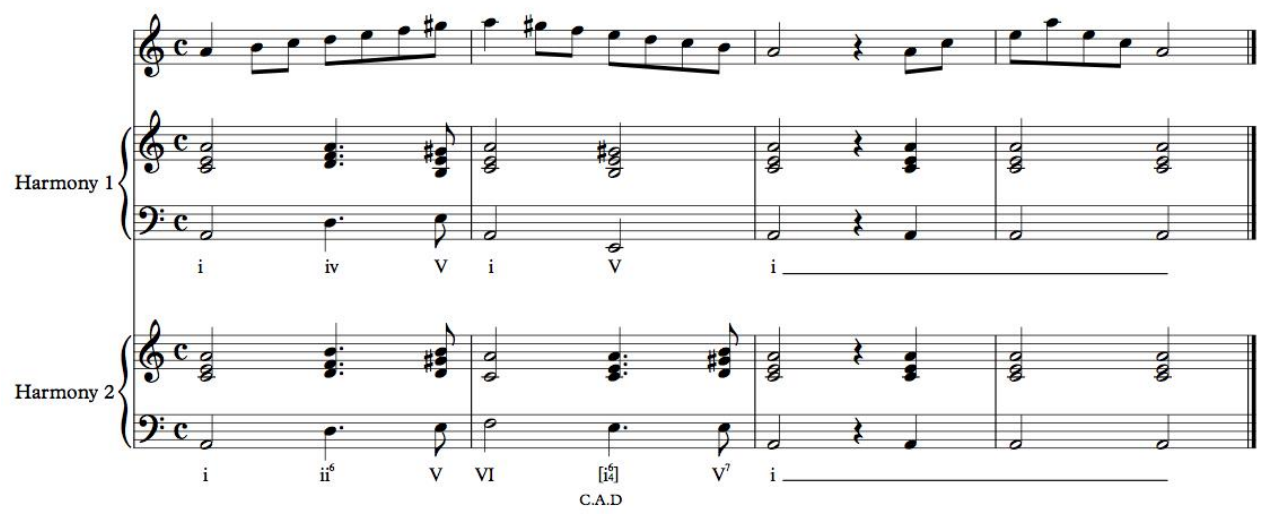

Figure 6. An example of a harmonised harmonic minor scale

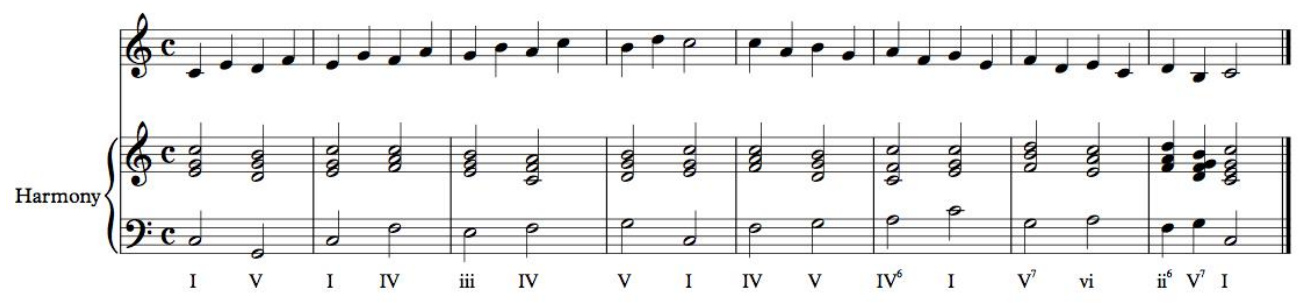

Figure 7. An example of a harmonised major scale played in thirds 


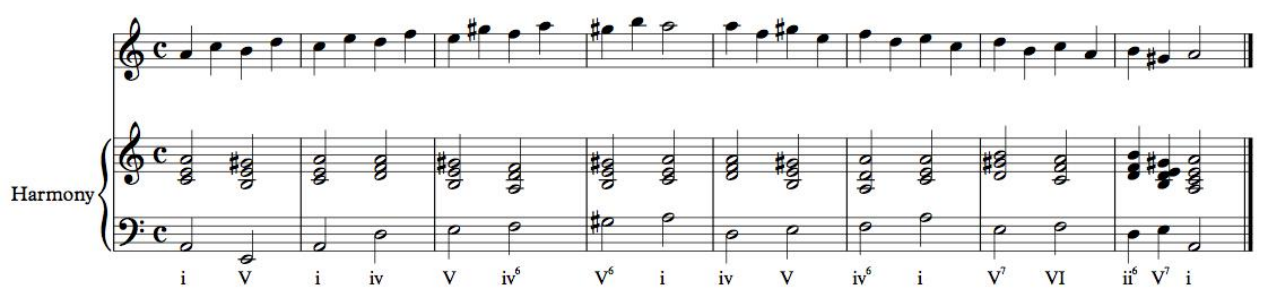

Figure 8. An example of a harmonised harmonic minor scale played in thirds

c) Phrasing: Adagio Cantabile (shown in Figure 9) was an eight-bar piece of music written specifically for this study by the composer Attakorn Sookjaeng. It was used to investigate how participants played a long melody based on the context of harmony.

\section{Adagio cantabile}
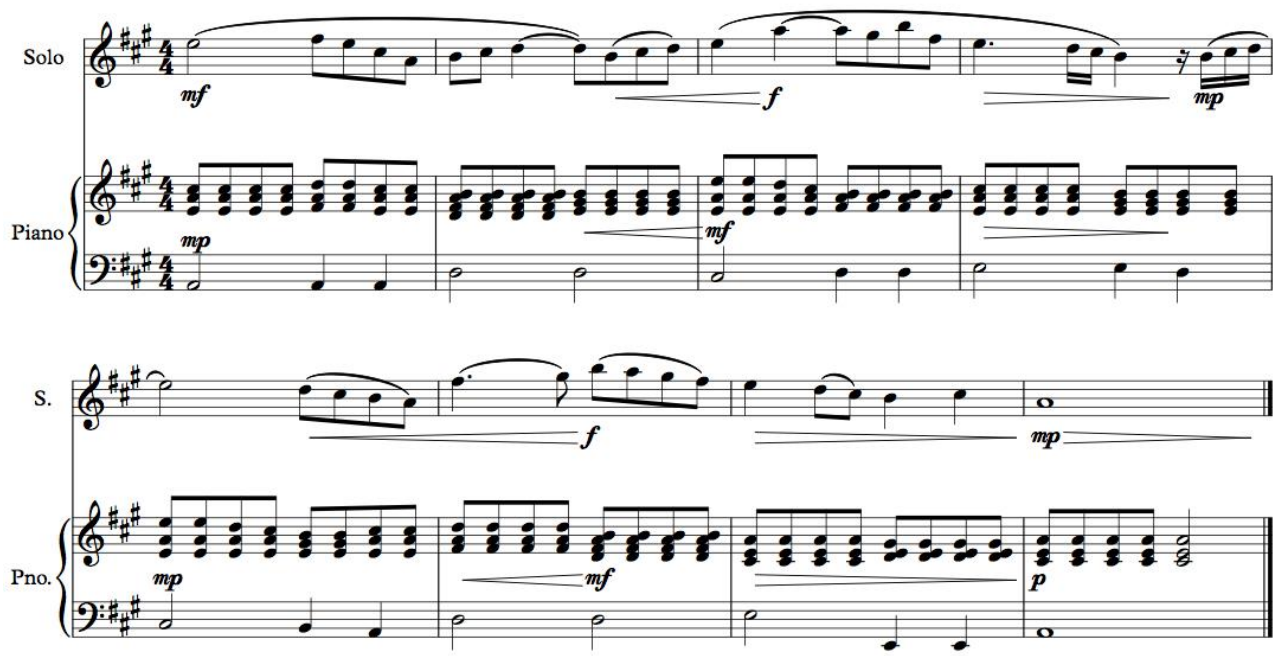

Figure 9. Adagio Cantabile by Attakorn Sookjaeng

Reference of Harmonic Sound (RHS). RHS is the harmonic structure that was provided with the basic technique exercises. The RHS provided a possible harmonic progression for each of the basic technique exercises.

Logic Pro X. It is a digital workstation that the researcher used to record the participants practicing the basic technique exercises. 


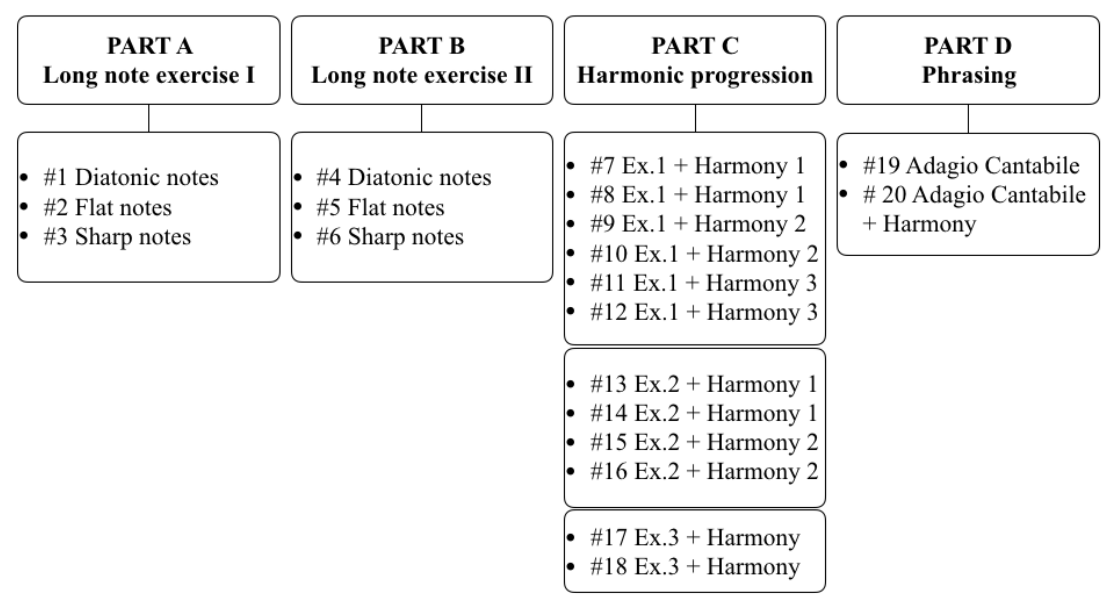

Figure 10. Practice observation plan

\section{Results and discussion}

The purpose of this study was to explore the ways in which developing students' aptitudes in listening for harmony might aid in improving their basic performance. The participants' results with regard to the basic wind techniques that were observed in the study - (a) long note, (b) scales, (c) phrasing — will be presented in this section.

\section{Long note}

This portion of the study consisted of long note exercise I and long note exercise II, each of which was divided into three sessions, which dealt with diatonic notes, flat notes and sharp notes.

Long note exercise I: to investigate how the participants listened in the context of harmony while playing a single note. In Long note exercise I, the participants were asked to play a single note while imagining a harmonic context of their own choice. Based on answers that the participants provided when asked at the beginning of the exercise whether they thought about harmony before playing, it was evident that they initially had a similar practice manner in which they mainly did not imagine the harmonic context before playing the notes. One of the participants answered the question rather meekly, saying, "I just played the note itself, I did not think about the chord or key". Another participant also said, "I did not consider the chord of the note and have never thought about it before". All of the participants agreed to try imagining the harmonic context again, however. Although the participants most often chose a harmonic context in which their note was simply the root of a triad, they began to demonstrate the potential, with repeated practice, to imagine a harmonic context before playing a note. 
Long note exercises II: to investigate how the participants played a single note based on a given harmonic context before and after listening to reference sounds. Before the participants listened to the reference of harmonic sounds (RHS), it was found that they had different ways of finding their notes based on the harmony, such as matching the pitch with their study pieces. One of the participants stated, "While I play this note, I tried to think about my solo pieces that start with the note G but I cannot remember what chord the piano part played". Another participant said, "I think about an arpeggio to understand the position of the notes".

After the participants played a note without listening for the RHS, the researcher provided an RHS and asked them to play the note again. All of the participants remarked that they felt a difference between when they played by themselves and then played after hearing the RHS. One participant mentioned that "It feels like a different note" and this is reflected in the more stable tone quality participants displayed after listening to the RHS. In Figures 11 and 12, the bluecolored sound waves correspond to participants 1 and 3 playing a single note four times before listening to the RHS, while the green-colored sound waves correspond to participants 1 and 3 playing a single note four times after listening to the RHS. In each of these figures, note the participants' improvements in consistency of tone after listening to the RHS - a smooth shape of the sound wave in the green box below.

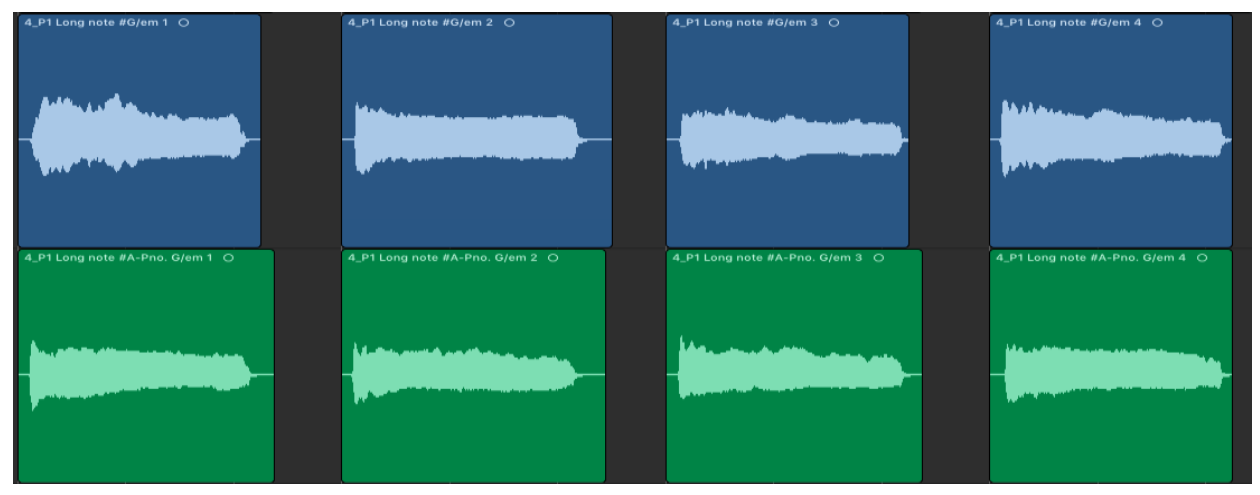

Figure 11. Comparison of Participant 1's stability of tone when playing a single note, before and after listening to the RHS 


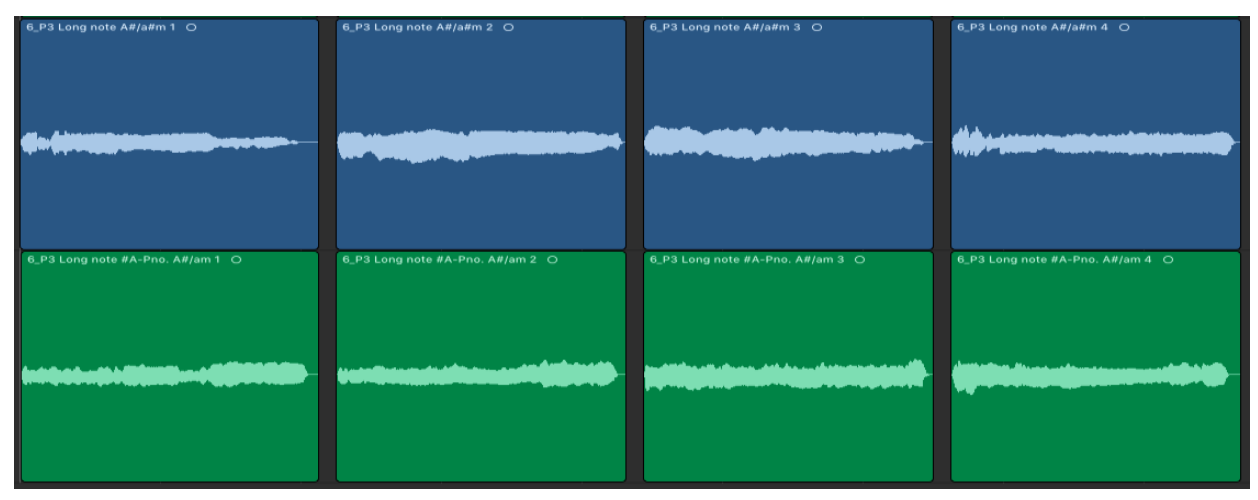

Figure 12. Comparison of Participant 3's stability of tone when playing a single note, before and after listening to the RHS

When trying to imagine the harmonic context before playing, participants tended to simply describe the tone color as bright or dark, which affected intonation as well (McGill, 2007). When playing major chord harmonies, the participants tended to play the notes brighter than necessary, which made them rather sharp, whereas when they chose a minor chord harmony, their intonation tended to be flatter than usual. During the long note exercise observation sessions, when the participants listened to the RHS and practiced the exercise accordingly, they gained a better awareness of their intonation. Overall, practicing long note exercises with the RHS appears to have benefited the participants with regard to tone quality and intonation.

\section{Scales}

Scales formed the most substantial part of the basic technique exercises, consisting of five-note patterns, major and minor scales, and third-interval scales, all of which were used with the purpose of investigating the participants' sense of melodic direction based on harmonic progression. The participants initially tended to hear the harmony rather than listening for it, paying more attention to fingering techniques, beats, and tempo rather than listening for harmonic movement. It was therefore clear that technical problems created significant barriers for the participants to developing their skills in listening for harmony, although in later observations each participant began to make progress in this respect.

Throughout the observations, participants were asked to play the scale exercises following a three-step process: 1) play the scale patterns on their own; 2) play along with an RHS, in the form of recorded tonal harmonic progressions; and 3) play the scale exercises on their own once again while trying to imagine the harmonic progressions they had been given in Step 2. The results from Step 2 of the process, in which participants were provided an RHS along with their scale exercises, showed that the participants began to infuse their scale playing with a greater sense of shaping and phrasing (especially toward the ends of phrases), 
corroborating the arguments of many writers - such as Roig-Francoli (2003), Karpinski (2000), and Naus (1998) - that playing scales with harmony can help make the melodic line more directed and meaningful. Figure 13 illustrates a couple of important aspects of Participant 3's playing with regard to the scale exercises. First, note the evolving sense of phrase shaping in Step 2 (see the green sound waves). Although the participant's playing in Step 3 (represented by the light blue sound waves) initially reverted to a melodic shape more resembling that from Step 1 (the dark blue sound waves), the phrase shapes eventually began to more closely approximate the sound waves from Step 2, exemplifying the participant's progress in recalling their sense of phrasing while playing with the RHS.

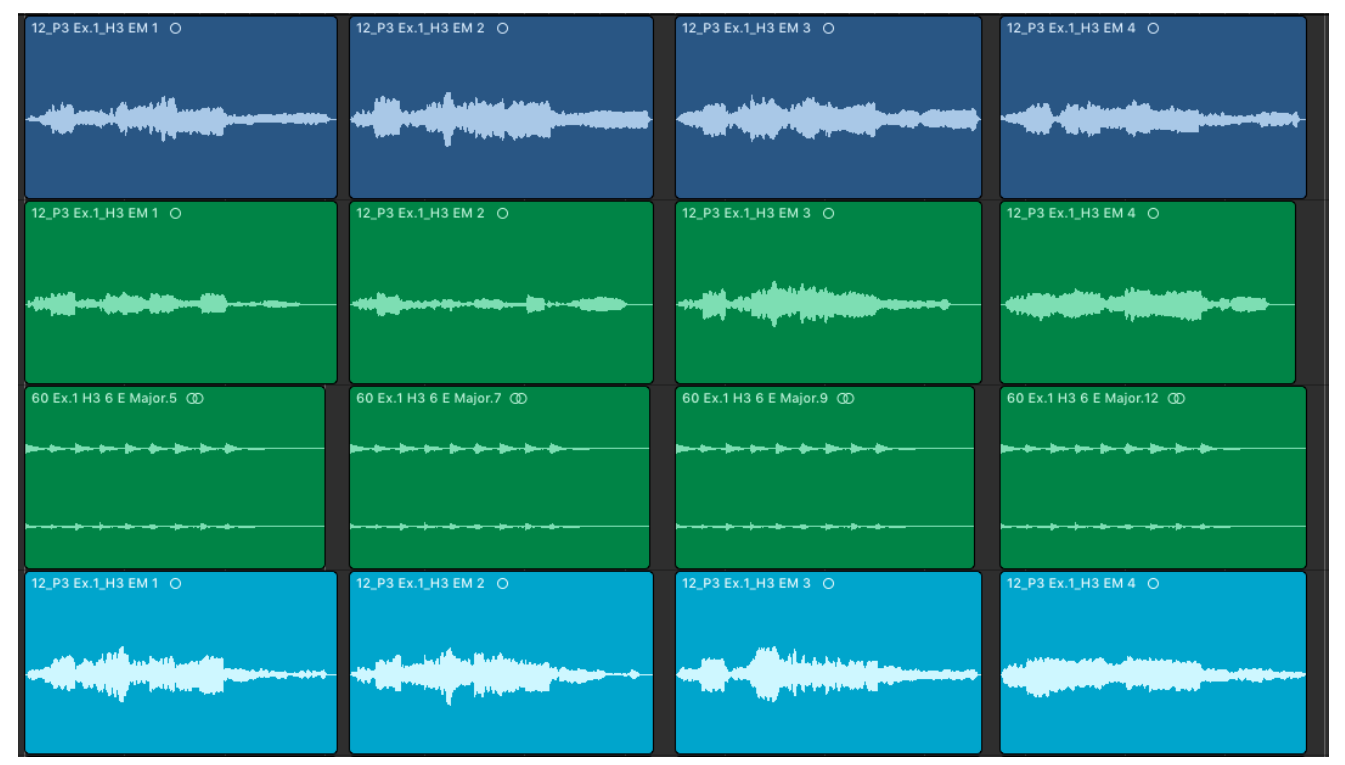

Figure 13. Sound waves from the five-note scale exercise of Participant 3

\section{Phrasing}

The short piece Adagio Cantabile was then used to investigate how participants played a long melody based on the context of listening for harmony. The results showed that listening for harmony helped the participants' sense of phrasing in two different ways.

First, Participant 2 mentioned, "I can play this piece in one breath, but when I listened for the harmony, I felt that I had to take a breath only this place and it made me play easier and understand the direction". As can be seen in the circled areas of Figure 14, it was clear that the participant found an appropriate place to breathe after listening for harmony, after not finding such a place the first time around. The sound waves shown in this figure thus support the notion that listening 
for harmony benefitted the participant with regards to a 'sense of phrasing'.

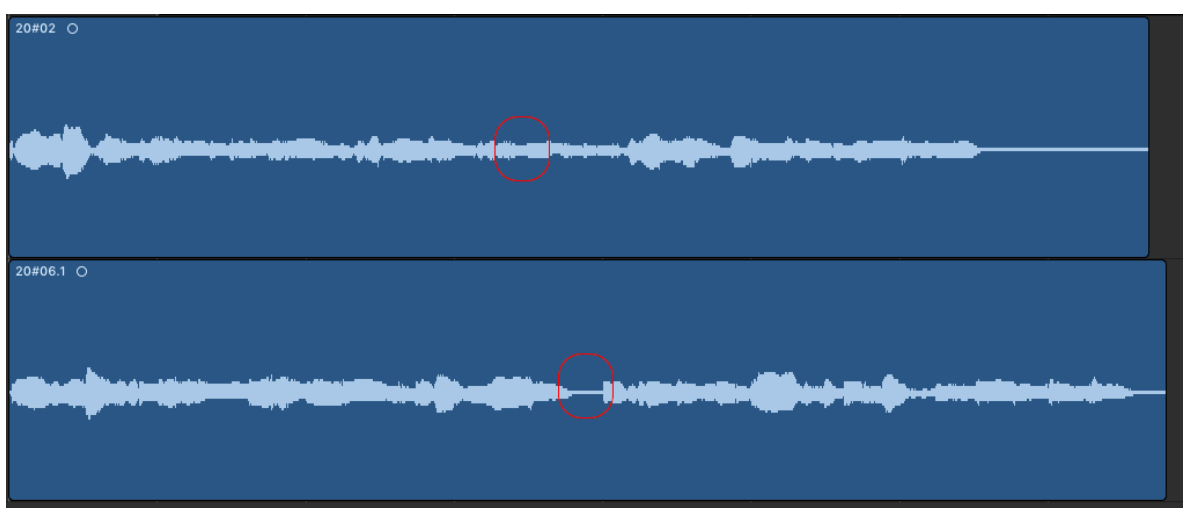

Figure 14. Participant 2's phrasing in Adagio Cantabile, before and after listening for harmony
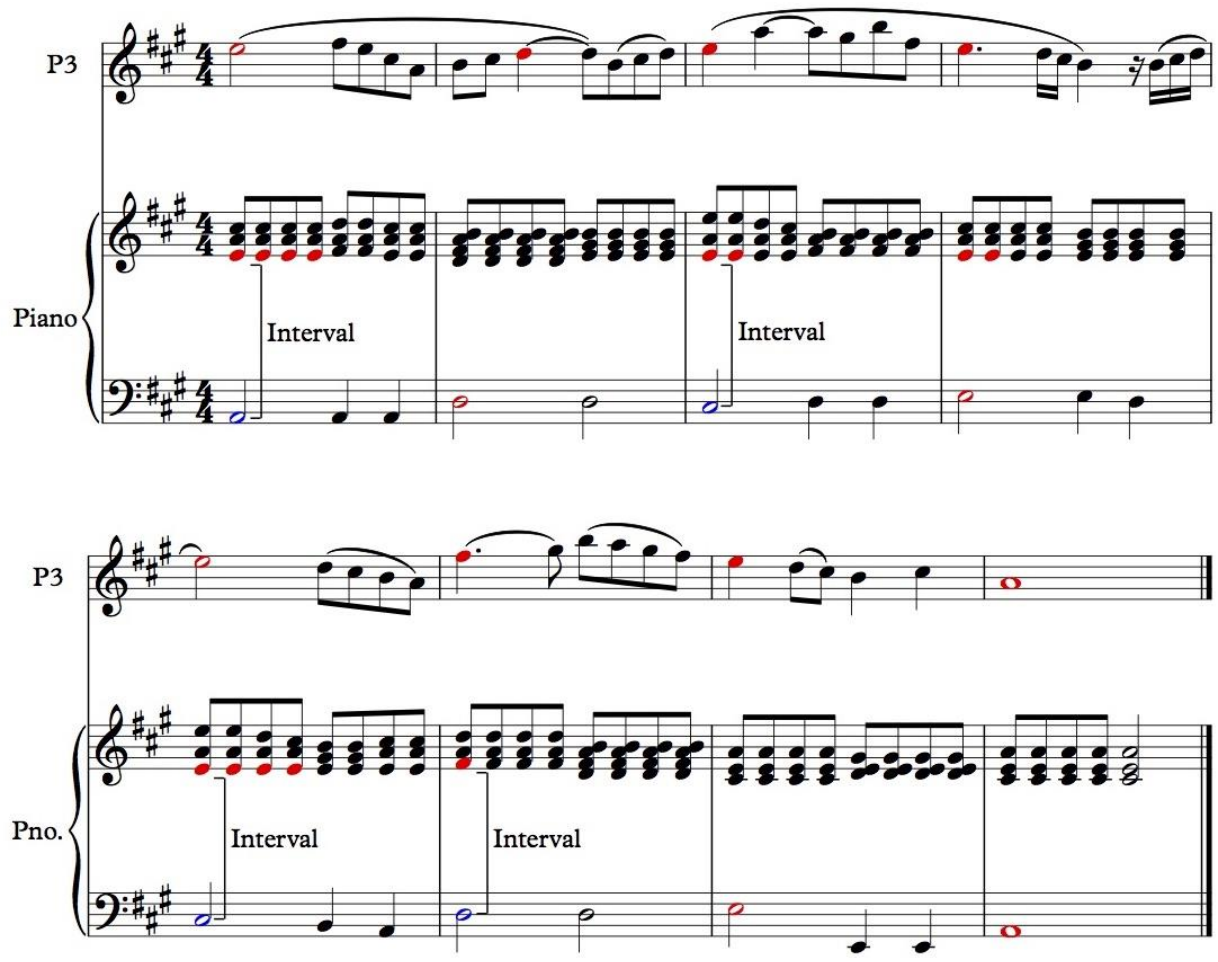

Figure 15. Notes that Participant 3 listened for in the piano accompaniment part of Adagio Cantabile 
Secondly, after first playing the melody alone, another participant then used the harmony to adjust their intonation, noting that "I listened for the note of the piano part that was the same as my solo part". Figure 15 shows the notes that Participant 3 listened for in the piano accompaniment part. An encouraging result can be found in the fact that the participant did not always simply try to listen for notes that matched the lowest or highest notes in the piano part; rather, the participant showed the ability to also listen for other notes within the chords that the piano played. Although this was initially an unfamiliar manner of practicing, the participant began to show an aptitude for thinking vertically (harmonically) as well as horizontally (melodically).

Figures 16 and 17 then compare the sound waves from when Participant 3 practiced the piece, first without accompaniment and then with accompaniment, indicating that listening for harmony the second time around helped the participant achieve a more directed, balanced sense of phrasing.

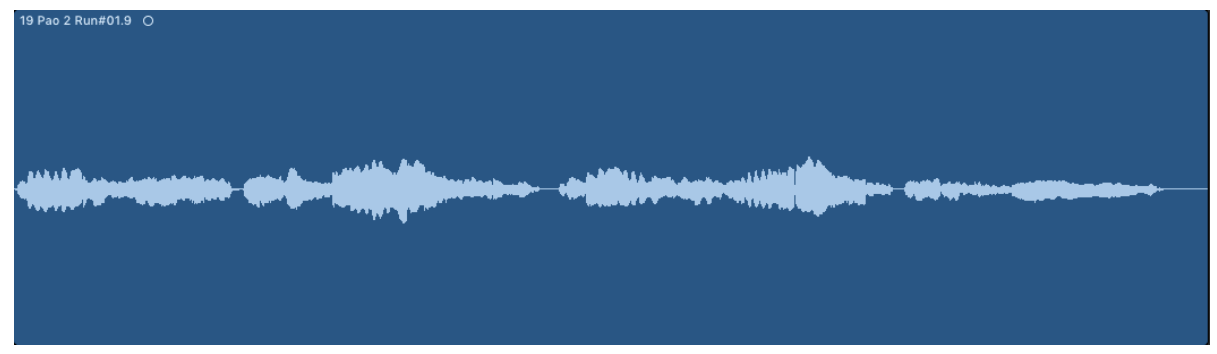

Figure 16. Participant 3's phrasing when playing Adagio Cantabile without accompaniment

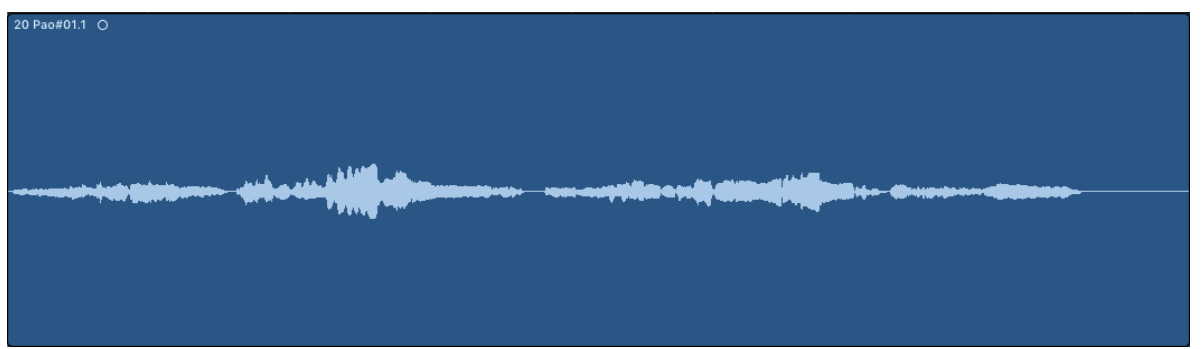

Figure 17. Participant 3's phrasing when playing Adagio Cantabile with accompaniment

\section{Conclusion}

The young wind instrument students who participated in this study freely admitted that they initially focused on playing their instruments without an awareness of the context of harmony. In addition, their notions of tone color were rather limited, and concerns about technique tended to supersede thinking about tone, intonation, and phrasing, which created certain barriers to developing their performance. As the participants became open to the idea of practicing single-line melodic patterns based 
on the context of listening for harmony, however, they demonstrated significant progress in the aforementioned areas and also began to develop increased confidence when playing their instruments (as summarised in Figure 18).

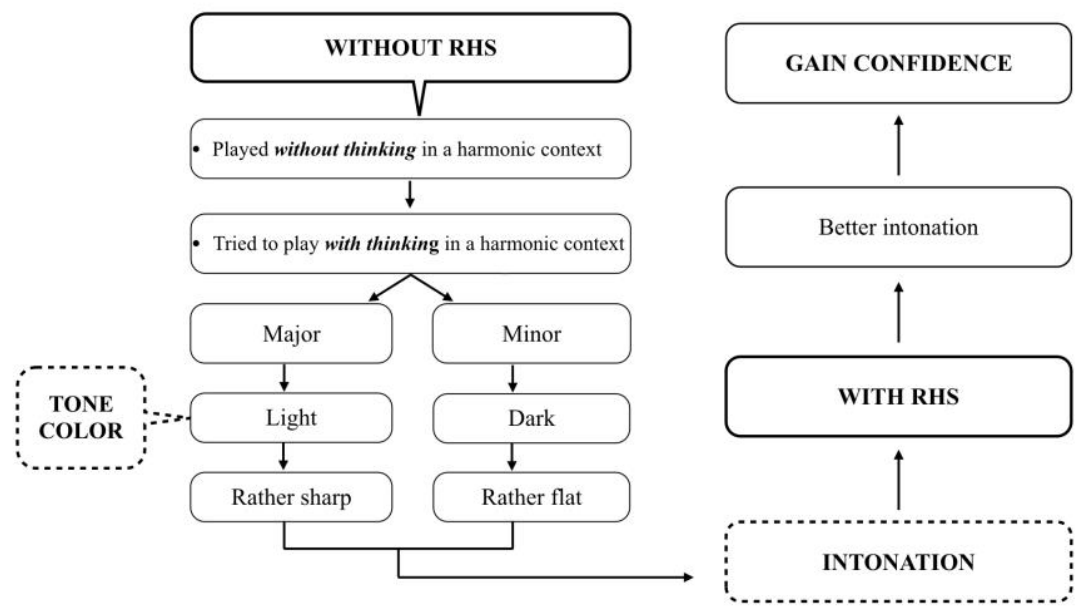

Figure 18. The process in which participants developed their skills in listening for harmony throughout the study and some notable results of the process

Although the participants initially lacked confidence in listening for harmony, by practicing with a reference of harmonic sound (RHS) they demonstrated the potential to improve their performance in a variety of ways. First, when the participants regularly practiced a single melodic line while listening for harmony, they were able to discover a means of improving their tone quality and intonation during performance. Second, by listening for harmonic progressions, the participants could begin to better understand the direction of a single melodic line, which led to being able to play the exercises with a greater awareness of phrasing. Furthermore, practicing in this manner helped reduce the pressure participants felt when playing difficult passages, as by shifting their focus from executing challenging technical skills to listening for harmony, the participants began to play phrases with a more directed flow from beginning until the end.

\section{Recommendations for Future Study}

While this study was limited to a group of selected participants from the Young Artists Music Program (YAMP) at the College of Music, Mahidol University (Thailand), it would be intriguing to explore how the ideas presented here could be applied to young wind instrument students in different locations and environments. In addition, the harmonic progressions used in this study were limited to basic tonal 
progressions; it would be of interest to explore how changing the scope in this respect would work with different groups of study participants. Finally, although the results of this study indicate that listening for harmony can be very beneficial in developing young wind instrument students' performance, it is also rather clear that for many inexperienced wind instrument students, understanding all of the ideas about practicing in this manner can be very difficult without guidance. This study has accordingly presented a step-by-step process by which young wind instrument students may work toward achieving this goal. Finding ways to incorporate this method of practicing into students' private instrument instruction and more generally into music education curricula is a clear goal for the future in order to develop new methods of music learning for young wind instrument students in Thailand.

\section{References}

Ashley, L. D. (2008). Case study research. In J. Arthur, M. Waring, R. Coe, \& L. V. Hedges, Research methods \& methodologies in education (pp. 102-107). London: SAGE Publications Ltd.

Creswell, J. W. (2013). Qualitative inquiry \& research design: Choosing among five approaches. California, CA: SAGE Publication, Inc.

Jensen, E. (2000). Listening and learning. In Music with the brain in mind (pp. 77). Thousand Oaks, CA: Corwin Press.

Karpinski, G. S. (2000). Aural skills acquisition: The development of listening, reading and performing skills in college-level musicians. New York, NY: Oxford University Press.

Kennedy, M., \& Kennedy, J. B. (2007). Phrase. The Concise Oxford Dictionary of Music (pp. 577). Oxford, New York, NY: Oxford University Press

Kim, J. N. (2013). Online processing of tonal melodies: Effects of harmonic expectations. ProQuest Dissertation \& Thesis. (ProQuest No. 1446721903).

Kostka, S., Payne, D., \& Almen, B. (2013). Harmony in Western music. In Tonal harmony: with an introduction to twentieth-century music (pp. xi-xiv). New York, NY: McGraw-Hill.

Laitz, S. G., \& Bartlette, C. (2010). Graduate review of tonal theory: a recasting of common-practice harmony, form and counterpoint. New York, NY: Oxford University Press.

Lisk, E. S. (1996). Listening and hearing. In The creative director: Intangibles of musical performance (pp. 24). Ft. Lauderdale, Fla.: Meredith Music Publications.

McGill, D. (2007). Sound in motion: A performer's guide to greater musical expression. Bloomington: Indiana University Press.

Naus, W. J. (1998). Beyond functional harmony. Advance music.

Rameau, J.-P. (1971). Treatise on harmony. New York, NY: Dover Publications.

Ratner, L. G. (1983). The musical experience: Sound, movement and arrival. New York, NY: W.H. Freeman.

Roig-Francoli, M. A. (2003). Harmony in context. Boston, MA: McGraw-Hill.

Sadie, S., \& Tyrrell, J. (2001). Phrase. In The new Grove dictionary of music and musicians (Vol. 19, pp. 633). New York, NY: Grove.

Servias, D. (2010). Towards confident and informed musicianship: A curricular synthesis of theory, ear training, and harmony, achieved through the acquisition of keyboard 
skills. ProQuest Dissertation \& Thesis. (ProQuest No. 275683757).

Taher, C. (2012). Pitch perception in changing harmony. ProQuest Dissertation \& Thesis. (ProQuest No. 1013441390).

Thailand International Music Examination (TIME). (2011). About TIME. Retrieved December 18, 2016, from TIME, Thailand International Music Examination: http://www.timemusicexam.com/en/about/about.php

Thomas, R. M. (1988). Approaches to gathering data: Case studies. In Conducting educational research: A comparative view (pp. 81). Westport, Conn.: Bergin \& Garvey.

Wedin, E. N. (2015). Listening - hearing. In Playing music with the whole body: Eurhythmics and motor development (pp. 35). Stockholm: Gehrmans Musikforlag.

Yin, R. K. (2009). Case study research: Design and methods. Los Angeles, LA: Sage Publications.

Young Artists Music Program (YAMP). (2018). Young Artists Music Program. Retrieved February 20, 2018, from Young Artists Music Program: https://www.music.mahidol.ac.th/yamp/

\section{Biography}

Prapassorn Puangsamlee is a Ph.D. candidate in music education from the College of Music, Mahidol University, Thailand. She has received a Master of Arts (Music) in Music Education and Bachelor of Music in Music Business from the College of Music, Mahidol University, Thailand. She is currently a teacher of Music for Early Childhood and flute teacher at the Music Campus for General Public (MCGP) Seacon Bangkae, Bangkok, Thailand, where she has taught since 2013. She has also taught in Music Campus for General Public (MCGP) Paragon and Seacon Square, Bangkok, Thailand. She has previously taught music subjects such as Teaching Practicum at the graduate level as well as Music Performance (Flute) and Small Ensemble (Flute ensemble) at the undergraduate level. Her areas of interests include topics in music in higher education, music education, music pedagogy and music business.

Kyle Fyr is the musicology department chair and the Master of Arts program chair at the College of Music, Mahidol University (Thailand). He received a PhD in music theory with doctoral minors in music history and piano performance from the Indiana University Jacobs School of Music in 2011, writing a dissertation focusing on proportionality and performance issues in piano works of John Adams. From 2011-13, he was an Assistant Professor of Music Theory at the University of Northern Colorado. He has presented papers at a variety of conferences throughout the US and UK, and has published in the Journal of Music History Pedagogy, the Malaysian Music Journal, Music Theory Online and Notes. He also has a forthcoming publication in the journal Music Theory and Analysis. 